\title{
Three rooted, four canalled mandibular first molar (Radix Entomolaris)
}

\author{
Parolia $\mathbf{A}^{1}$, Kundabala $\mathbf{M}^{2}$, Thomas MS ${ }^{1}$, Mohan $\mathbf{M}^{3}$, Joshi $\mathrm{N}^{4}$ \\ ${ }^{1}$ Assistant Professor, ${ }^{2}$ Professor and Head, ${ }^{4}$ Specialist Resident, Department of Conservative Dentistry and Endodontics, \\ ${ }^{3}$ Assistant Professor, Department of Prosthodontics, MCODS, Mangalore India.
}

\begin{abstract}
A mandibular first molar with two distal roots is an interesting example of anatomic variation. This paper describes case reports of mandibular first molar with three roots (one mesial and two distal) and four canals (two in mesial and one in each distobuccal and distolingual root). The canals were shaped with protaper rotary files and irrigated with $5.25 \%$ sodium hyochlorite, $0.2 \% \mathrm{w} / \mathrm{v}$ of chlorhexidine gluconate and normal saline as the final irrigant. The canals were then obturated with gutta- percha and AH plus sealer. These case reports show an anatomic variation of internal morphology of the tooth and points out the importance of searching for additional canals.
\end{abstract}

Key words: Mandibular first molar, two distal roots, four canals

For root canal treatment to be successful, it is necessary to locate all root canals, debride them thoroughly and seal them completely with an inert root filling material. Unfilled canals remain a nidus for infection and can compromise treatment outcome. A clinician should be aware of the internal morphology of permanent teeth and the possible variations which may be encountered. Permanent first molar teeth are frequently affected by caries at an early age and may require root canal treatment for long-term retention. The morphology of both permanent first molars has been studied and it is accepted that the mesiobuccal root of maxillary first molars and the distal root of mandibular first molars often have more than one canal. In general, the second canal of the distal roots of mandibular first molars is more easily located and treated than the second canal in the mesiobuccal root of maxillary first molars which tends to be elusive ${ }^{1}$. Recent studies reported a higher incidence of second canals in distal roots of mandibular permanent first molar than earlier studies ${ }^{2,3,5,6}$ (Table 1). This could be due to better awareness of morphology amongst clinicians and to a change in the shape of access cavities to a more rectangular form as compared with the earlier triangular shape recommended. One other reason could be its inherent higher distribution in certain populations. Studies amongst the Asian populations have shown a greater tendency for a second canal in the distal roots of mandibular first molars compared with other populations ${ }^{7}$. This is also true with in laboratory studies (Table 1).The presence of two distal roots is rare but does occur. This additional root that can usually be found distolingually was first mentioned in literature by De Moore et $\mathrm{al}^{8}$ was called "radix entomolaris" (RE) ${ }^{9}$. An $\mathrm{RE}$ was found on the first, second and third mandibular molars, occurring least frequently on the second molar?. Some studies reported a bilateral occurrence of the RE from $50 \%$ to $67 \%{ }^{10,11}$. The presence of three rooted mandibular first molar appears to be less than $3 \%$ in blacks $^{12}$, about $3 \%$ to $4.2 \%$ in whites ${ }^{13}$, less than $5 \%$ in Eurasians and Asians populations, and approximately 5 $\%$ to more than $30 \%$ in mongoloid traits ${ }^{10,14}$ (Table 2 ).

The present report describes two rare cases which have undergone root canal treatment in mandibular first molar with three roots (one mesial, two distal that is distobuccal and an additional distolingual (radix entomolaris -type I) and four canals (two mesial and two distal).

\section{Case 1}

A 35 year old male patient was reported to the Department of Conservative Dentistry and Endodontics, Manipal College of Dental Sciences, Mangalore, India with a complaint of pain on chewing in right lower back tooth. On clinical examination there was gross decay in mandibular right first permanent molar (\#46).

\footnotetext{
Correspondence

Dr. Abhishek Parolia

Assistant Professor, Department of Conservative Dentistry and Endodontics,

Manipal College of Dental Sciences, Mangalore

Karnataka-575001, India

E-mail: paroliaabhi@yahoo.com
} 
Tooth showed negative response on vitality testing, and was tender on percussion. Intra oral periapical radiograph revealed the presence of peri-apical radiolucency around both mesial and distal roots. This radiograph also showed that the tooth had an additional distolingual root (Fig 1a). Diagnosis of symptomatic apical periodontitis was made and root canal treatment was recommended. Local anesthesia (inferior alveolar nerve block) was performed. The tooth was isolated by a rubber dam, and then the access cavity was prepared with distolingual extension to provide proper access to distolingual canal. After finding orifices of the canal, a radiograph was taken to determine the working length of the canals with two instruments in mesial root and two instruments in the distal roots. Shaping and cleaning was performed using rotary pro-taper files (DENTSPLY, Maillefer, Swiss made CH-1338 Ballaigues) in crown down manner. Apical preparation was done till size F3 protaper file (master apical file). The canals were irrigated with $5.25 \%$ sodium hypochlorite, $0.2 \% \mathrm{w} / \mathrm{v}$ chlorhexidine gluconate (Vishal Dentocare Pvt, Ltd India) during instrumentation and finally with normal saline. The canals were then dried with paper points, master cone selection radiograph was taken, and obturated with laterally condensed gutta percha (DENTSPLY, Maillefer, Swiss made CH-1338 Ballaigues) and AH plus sealer(DENTSPLY DeTrey GmbH, Germany) (Fig 1b). Post endodontic restoration was placed and patient was recalled for follow up and full coverage crown.

Case 2

A 28 year female patient was referred to our department for root canal treatment of right mandibular first molar (\#46). A general practitioner had started the root canal treatment, but could not find all the root canals. The tooth was asymptomatic and free of any clinical signs, including tenderness on percussion, but pretreatment radiograph disclosed widening of periodontal ligament space. The diagnosis was asymptomatic apical periodontitis and root canal treatment was recommended. Like case 1, diagnostic radiograph showed presence of two distal roots (Fig 2a). Root canal procedure was performed similar to case 1 (Fig 2b). Post endodontic restoration was placed and patient was recalled for follow up and full coverage crown.

Table 1: Incidence of two canals in distal root of mandibular first molar

\begin{tabular}{|l|c|c|}
\hline Author/ Year & Incidence (\%) & Population group \\
\hline Skidmore and Bjorndal (1971) & 28.9 & Caucasians \\
\hline Vertucci and Williams(1974) & 30 & Caucasians \\
\hline Yew and Chan (1993) & 31.5 & Chinese \\
\hline Zaatar et al (1997) & 29.9 & Middle East \\
\hline Gulabivala et al (2001) & 20 & Burmese \\
\hline Gulabivala et al (2002) & 33.4 & Thai \\
\hline Sen et al (2004) & 46 & Turkish \\
\hline
\end{tabular}

Table 2: Prevalence of three rooted mandibular first molars- survey of available studies

\begin{tabular}{|l|c|c|}
\hline Author/year & Prevalence (\%) & Population group \\
\hline Taylor (1899) & 3.4 & United Kingdom \\
\hline Tratman (1938) & 5.8 & Chinese \\
\hline Tratman (1938) & 0.2 & Indians \\
\hline Skidmore and Bjorndal (1972) & 2.2 & Caucasians \\
\hline Yones et al (1990) & 2.92 & Saudi \\
\hline Loh (1990) & 7.9 & Chinese (Singapore) \\
\hline Yew and Chan (1993) & 21.5 & Chinese \\
\hline Sperber and Moreau (1998) & 3.0 & Senegalese \\
\hline Gulabivala et al (2001) & 10.1 & Burmese \\
\hline
\end{tabular}




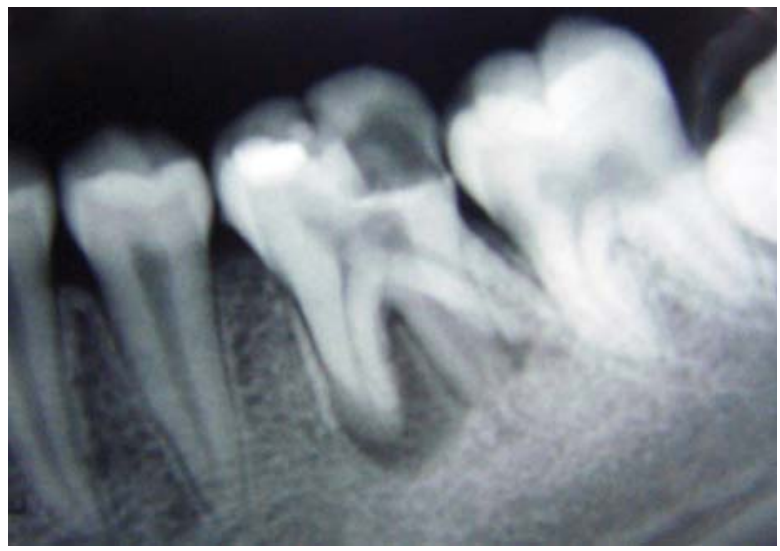

Fig 1a: Diagnostic radiograph; an additional distal root was presented

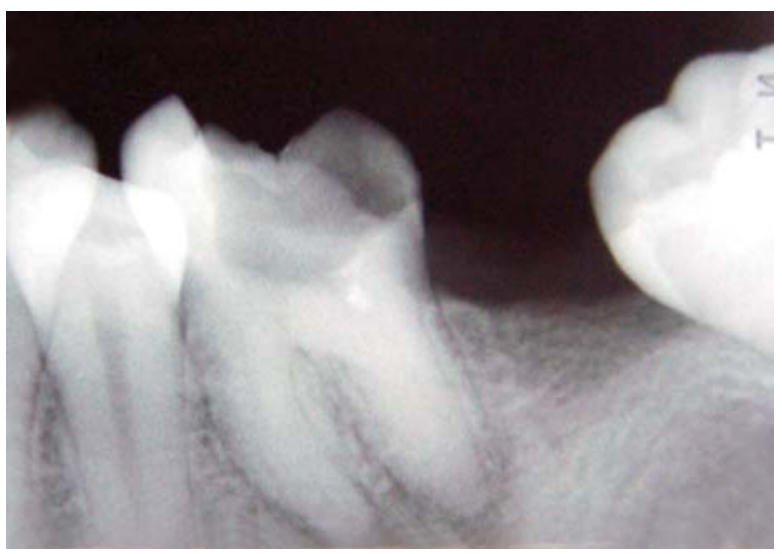

Fig 2a: Diagnostic radiograph; an additional distal root was presented

\section{Discussion}

The internal anatomy of tooth is not always similar. A great number of variations could occur in number of roots and their shape. Most dentists are used to treating normal roots with similar traits; as a result, many failures can occur. However it must be noticed that abnormalities are rare, but it is possible that a patient referred may have one of these rare anatomic variations. The above case reports remind us that during each procedure we must expect variations, which may affect the treatment outcome. These case reports have described mandibular first permanent molar with one mesial root and two distal roots (distobuccal and distolingual). The mesial root had two canals (mesiobuccal and mesiolingual) and two distal roots with one canal each. One of the variations that can occur in mandibular first molars is radix entomolaris ${ }^{9}$. RE is a supernumerary distolingual root with various occurrences in different populations ranging from $3 \%$ of the African population ${ }^{12}$ to more than $30 \%$ of the mongoloid population ${ }^{14}$. The etiology behind the formation of RE is still unclear. In dysmorphic

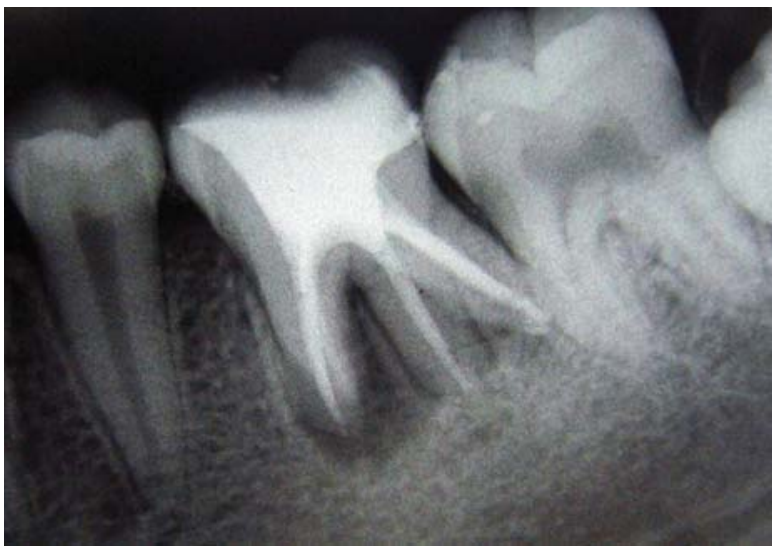

Fig 1b: The final radiograph; all four canals obturated

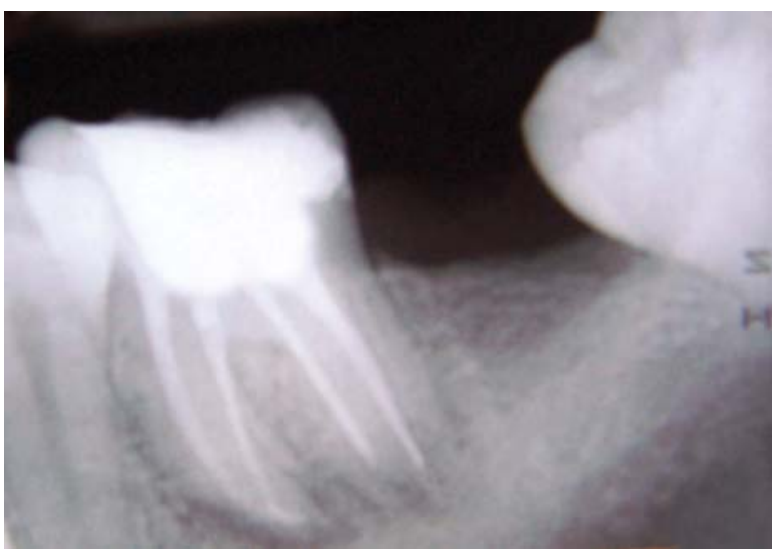

Fig 2b: The final radiograph; all four canals obturated

supernumerary roots, its formation could be related to external factors during odontogenesis or presence of an atavistic gene or polygenetic system ${ }^{8}$. According to Quackenbush $^{15}$, the extra root occurred unilaterally in approximately $40 \%$ of all cases and predominantly on the right side. This is also likely to be true, because we found both these cases on the right side. The incidence of first mandibular molars with three distal roots is unknown. In cases of a mandibular first molar with two distal roots, the distolingual root is smaller than the distobuccal root and is usually curved ${ }^{16}$. But in these present cases both distoligual roots were straight (type-I radix entomolaris $)^{8}$. In most right mandibular molar with two distal roots, a clinician should always check for an additional canal especially in distobuccal root. There are various methods to locate additional canals, these are as follows-

1. Knowledge of law of symmetry and law of orifice location $^{17}$

2. Tactile sensation with hand instrument 
3. Using various instruments like endodontic explorer, path finder, DG 16 probe and mico-opener

4. Champagne effect- bubbles produced by remaining pulp tissue in the canal, while using sodium hypochlorite in pulp chamber

5. Introral periapical radiograph

6. Digital radiography

7. Using fiber-optic illumination dental edoscopy and orascopy

8. Using surgical loupes

9. Using Operating microscope

10. Micro Computed Tomography

11. Visualization endograph using Ruddle's solution

12. Magnetic Resonance Microscopy

Both cases presented here had only single canal in distobuccal and distolingual root.

\section{Conclusion}

The high frequency of a fourth canal in mandibular first molars makes it essential to anticipate and find all canals during molar root canal treatment. The possibility of an extra root should also be considered and looked for carefully. Proper angulation and interpretation of radiographs help to identify chamber and root anatomy. In the case of an RE the conventional triangular opening cavity must be modified to a trapezoidal form in order to better locate and access the distolingually located orifice of the additional root.

\section{References}

1. Hartwell G, Bellizzi R. Clinical investigation of in vivo endodontically treated mandibular and maxillary molars. J Endod. 1982; 8:555-7.

2. Al Nazhan S. Incidence of fourth canal in root canal treated mandibular first molars in a Saudi Arabian sub-population. Intl Endod J. 1999; 32: 49-52.

3. Gulabivala K, Aung TH, Alavi A, Ng YL. Root and canal morphology of Burmese mandibular molars. Int Endod J. 2001; 34:359-70.

4. Wasti F, Shearer AC, Wilson NHF. Root canal systems of the mandibular and maxillary first permanent molar teeth of south Asian Pakistanis. Int Endod J. 2001; 34:263-6.
5. Gulabivala K, Opasanon A, Ng YL, Alavi A. Root and canal morphology of Thai mandibular molars. Int Endod J. 2002; 35:56-62.

6. Sert S, Aslanalp V, Tanalp J. Investigation of the root canal configurations of mandibular permanent teeth in the Turkish population. Int Endod J. 2004; 37: 494-9.

7. Pattanshetti1 N, Gaidhane1 M, Al Kandari A. M. Root and canal morphology of the mesiobuccal and distal roots of permanent first molars in a Kuwait population - a clinical study. Int Endod J. 2008; 41:755-62.

8. De Moore RJ, Deroose CA, Calberson FL. The radix entomolaris in mandibular first molar: an endodontiic challenge. Int Endod J. 2004; 37:789-99.

9. Calberson FL, De Moore RJ, Deroose CA. The radix endomolaris and paramolaris: clinical approach in endodontics. J Endod. 2007; 33:5863.

10. Yew SC, Chan K. A retrospective study of endodontically treated mandibular first molars in Chinese population. J Endod. 1993; 19:471-3.

11. Steelman R. Incedence of an accessory distal root on mandibular first permanent molars in Hispanic children. ASDC J Dent Child. 1986; 53:122-3.

12. Sperber GH, Moreau JL. Study of the number of roots and canals in Senegalese first permanent mandibular molars. Int Endod J. 1998; 31:117-22.

13. Curzon ME. Three rooted lower molars in man and their racial distribution. Br. Dent J. 1973; 52:181-3.

14. Walker RT, Quackenbush LE. Three rooted lower first permanent molars in Hong Kong Chinase. Br. Dent J. 1985; 159:298-9.

15. Quackenbush LE. Mandibular molar with three distal root canals. Dent traumatol. 1986; 2: 48-9.

16. Weine FS. Access cavity preparation and initiating treatment. In: Weine FS, ed Endodontic Therapy, 3rd edition. St. Louis, USA: The C. V. Mosby Company. 1982. p.207-55.

17. Krasner P, Rankow H. Anatomy of pulp chamber floor. J Endod. 2003; 30(1):5-16. 